\title{
Mechanical Properties of Eichhornia Crassipes Fiber as Lost Circulation Material for Oil and Gas Drilling Application
}

\author{
Purnomosidi ${ }^{1,{ }^{*}}$ Waheed Afzal ${ }^{2}$ Paul D. Hallett ${ }^{3}$ Erdila Indriani ${ }^{1}$ \\ ${ }^{1}$ Oil \& Gas Production Engineering, PEM Akamigas, 58315, Indonesia \\ ${ }^{2}$ School of Engineering, University of Aberdeen, AB24 3UE, United Kingdom \\ ${ }^{3}$ School of Biological Sciences, University of Aberdeen, AB24 3UU, United Kingdom \\ *Corresponding author. Email: purnomosidi@esdm.go.id
}

\begin{abstract}
In Indonesia, people have long been produced Eichhornia Crassipes Plant (ECP) stalks as raw materials for handicraft products. Other research has demonstrated that the tensile testing of individual fibers provides relevant data to assess their integrity in drilling mud. Whilst data on the mechanical properties of other natural fibers used as lost circulation material in drilling mud have been collected, the behavior of ECP is unknown. This study proposes an alternative solution to combat the vast growth of this invasive species through utilizing it as lost circulation material for oil and gas drilling operations. The plant fragments studied originated from plant stalks and were extracted as individual fibers. The study describes tensile tests to characterize stiffness and strength. Mechanical tests were conducted on ECP fibers to determine their stiffness under dried and water-wet conditions. Initial tensile tests on nylon fiber determined potential experimental artifacts with the experimental approach. The dried fibers had a water content of 8.163 wt. \% (SE 0.636), whereas the wet fibers were 93.43 wt.\% (SE 0.294). Water wet fibers had a lower modulus of elasticity than dried fibers and therefore, dried fibers have less tensile strength than wet fibers (Mean = 45.16 M Pa- SE $=5.023-\mathrm{N}=41$ ).
\end{abstract}

Keywords: Eicchornia Crassipes, Tensile Test, Lost Circulation, Fibre, Drilling Mud.

\section{INTRODUCTION}

Drilling mud refers to fluids that have been used in the rotary drilling process to perform good drilling practices [1]-[3]. In drilling operations for oil and gas, an overbalance condition occurs if the hydrostatic pressure is greater than the formation pressure of the pore fluids [1], [2]. This differential pressure pushes drilling mud filtrates into permeable layers through pores. Solid particles left behind at the face of the borehole form web like structures where fines and other smaller solid particles deposit in the interstices of remaining spaces, settling out to create a deposit of a mud cake that retains further invasion of the drilling mud filtrates into the formation, while maintaining the borehole stability [1], [4].

The presence of larger fractures along the borehole, which can form either naturally or be induced by drilling, presents a significant challenge as drilling mud can escape under pressure. Traditionally used solid particles (e.g. bentonites) in drilling mud are unable to settle out to form mud cakes in front of fracture zones due to the much larger size of the opening relative to the solid particles. This process, referred to as lost circulation, can hinder the effectiveness of drilling mud. Drilling mud invasion through fracture zones is costly and decreases the effectiveness of drilling, so preventative measures are necessary [5]. Lost circulation materials that have properties to shut off the loss zones created by larger fractures are commonly used [5], [6].

Whilst many of these materials will be man-made and costly, there is growing use and commercialization of natural inclusion [3], [7]-[11]. Many natural inclusions are plant-based fibers. Sugar cane fibers (bagasse), coconut coir, rice straw and husk, sawdust, and wood bark and fibres are commonly used to mitigate the problem. When mixed with drilling mud the fibres decrease lost circulation by creating a mesh of fibres across larger fractures. Ideally, they have the ability to form bridge-like networks in front of the fracture zones. This provides a base structure for other solid particles to settle out in between the fibres of the mat to build tight 
mud cakes that filter drilling mud flow to the fractured formation and thereafter completely shut off the lost zones [12].

Plant fibres are abundant and easy to produce from a range of agricultural by-products. However, an even more sustainable and cost-effective approach of harvesting plant fibres could target invasive species, thereby providing cost-recovery from conservation measures that remove these damaging plants from the environment.

In Indonesia, a prolific invasive plant is ECP. The species is categorized as one of the 10 major weeds occurring in Indonesia [13], following its introduction into the country as an ornamental plant in the Bogor Botanic Garden in 1894 [14], [15]. Local communities have utilized ECP at limited level for handicraft products to generate income [13]. Recently, researchers have studied this invasive weed for more technical benefits such as health and medicines, renewable energy, agricultures and fisheries, and engineering applications. Some benefits are already previously harvested from this invasive species, but the potential use as a drilling mud additive to decrease lost circulation has not been investigated in detail.

In this study, the tensile properties of ECP fibers are reported, building on the knowledge of the behavior of other natural materials that are currently used as lost circulation materials. Tests are conducted in a dry and wet condition, with careful measurement of diameter to observe whether changes with size follow the same trends that were found for other fibers. These data are essential for assessing the integrity of fibers used during the drilling process.

\section{METHOD}

The Individual fibres were tensile tested using a Zwick all round $5 \mathrm{kN}$ loading frame fitted with a $5 \mathrm{~N}$ load cell accurate to $0.05 \mathrm{mN}$ at maximum load (Zwick Roell AG, Ulm, Germany). Data on applied force and crosshead displacement were logged to a computer and analysed using Zwick TestExpert ${ }^{\circledR I I}$ software. The test sequence loaded the fibre at $50 \mathrm{~mm} / \mathrm{min}$ until $0.04 \mathrm{~N}$ was reached to rapidly take up a slack, and then slowed to 2 $\mathrm{mm} / \mathrm{min}$ after pre-load. Samples that did not fail at the centre point between the grips were rejected from analysis. For wet fibres, 41 out of an initial 60 specimens were used successfully to determine the modulus of elasticity and tensile strength. Dried fibres were more difficult to test, with only 15 successful experiments out of an initial 60 specimens.

From data on applied force, displacement and fibre diameter, tensile strength and young's modulus were determined. Young's modulus was determined from the slope of the initial linear region of the stress vs strain curve, as follows:
Applied force, $F$ was translated to stress, $\sigma$ by dividing by fibre cross-sectional area, A:

$\sigma=\frac{F}{A}$

From this the tensile strength was taken as the maximum stress before breakage. Strain, $\varepsilon$ was calculated by:

$\varepsilon=\frac{\Delta L}{L_{0}}$

where

$\Delta L=L_{1}-L_{0}$

When strains are small, the strain is very nearly proportional to the stress. That is, they are linear elastic. For simple tension:

$\sigma=E \epsilon$

Tensile strength of the fibre was calculated as follows:

$T=\frac{F}{A}$

where:

$\mathrm{E} \quad=$ Young's modulus GPa

$\mathrm{T}=$ tensile strength, $\mathrm{Pa}$

$\mathrm{F} \quad=$ force to failure, $\mathrm{N}$

A $=$ cross sectional area at failure plane, $\mathrm{m} 2$

$\Delta L=$ The change in fibre length, $\mathrm{m}$

$L_{0} \quad=$ Initial length, $\mathrm{m}$

The test method has limitations as it determines young's modulus at ambient temperature and assumes the fibre has a homogeneous shape and isotropic properties. The tests are also conducted under a constant cross head displacement rates $2 \mathrm{~mm} / \mathrm{min}$ at quasi-static loading conditions that may not reflect dynamic stresses experienced in drilling muds under high flow rates and pressures.

As an approximation, each fibre was assumed to have a cylindrical shape and homogeneous diameter along its length. The diameter was measured at the point of breakage using an inverted graticule microscope with $40 \mathrm{x}$ magnification.

The water content of the wet and dried fibres was determined by oven drying at $105{ }^{\circ} \mathrm{C}$ for 24 hours. Samples were first cooled in a desiccator before weighing to $0.001 \mathrm{~g}$ accuracy. There were 3 replicates from wet and dried fibres measured. The dried fibres had a water content of 8.16 wt. \% (SE 0.636), whereas the wet fibres were 93.43 wt.\% (SE 0.294).

Nylon as a synthetic and homogenous fibre was used to evaluate the repeatability of measurement with the tensile testing apparatus and mounting grips. The nylon 
had a diameter $0.41 \mathrm{~mm}$ measured by a digital Vernier caliper. The setup was identical to the plant fibres tensile testing experiments, except that a higher capacity $5 \mathrm{kN}$ load cell and stronger pneumatic grips were required due to the strength of the nylon.

\section{RESULT AND DISCUSSION}

Each stress-strain curve consisted of an initially linear slope followed by a curvature indicating a disproportionate increase in strain with stress until the fibre breaks. Modulus of elasticity was determined from the initial linear slope determined on each graph. Figure 1 shows the stress-strain curve of wet fibres shows higher values than the dried fibres. Dried fibres on Figure 2 had strain values up to $0.5 \%$, whereas for wet fibres the maximum strain was up to $6 \%$.

A Fischer test and a fitted-line model were performed to check the relationship between the diameter of fibres and their moduli of elasticity. In this study, we used Minitab $^{\text {TM }}$ to do the statistical analysis. We put modulus of elasticity values as a response and fibre diameter as the factor. The ANOVA test gives $\mathrm{F}$ and $\mathrm{P}$ value to both groups that we can analyse further to accept or reject the null hypothesis. Furthermore, Figure 4 shows that the modulus of elasticity of dried and wet fibres decreased as diameter increased.

Goodness of fit tests showed the histogram of both groups fit with a 3 parameter Weibull distribution. The wet fibres group had a lower rate of failure $(P>0.005$, $\mathrm{AD}=0.3$, shape or $\mathrm{m}=1.054)$ than dried fibres $(\mathrm{P}=$ $0.315, \mathrm{AD}=0.438$, shape or $\mathrm{m}=1.365$ ), suggesting that the dried fibres arranged as a mat of many fibres would be more likely fail progressively under pressure.
A similar pattern occurred for strength, with dried fibres having a maximum stress up to $25 \mathrm{MPa}$ less than the $140 \mathrm{MPa}$ failure stress measured for wet fibres. Figure 5 shows from a fitted line model the tensile strength of dried $(\mathrm{S}=4.946 ; \mathrm{R} 2=45.9 \%)$ and wet fibres $(\mathrm{S}=19.878 ; \mathrm{R} 2=62.8 \%)$ in relation to fibre diameter. It shows that wet fibres have higher tensile strength than dried fibres.

However, the nylon showed a different pattern, as seen in the Figure 3. As a synthetic fibre, it has a normal distribution. Thirty-two specimens were tested, and the mean of the modulus of elasticity was $2.12 \mathrm{GPa}$. This value is similar to other study [16], verifying that the apparatus and the mounting grip method produces reliable results. The stiffness and strength measurements found in this study were similar to tensile properties of other natural fibres [17], [18]. These authors also found a characteristic increase in strength with decreasing fibre diameter, indicating that the size distribution of fibres used as a lost circulation material will have a significant impact on their effectiveness.

According to results, it is noticeable that modulus of elasticity of ECP fibres decreased with increasing fibre diameter. Dried fibres were significantly stiffer and stronger than water saturated fibres. In this study, the results may be due to the measurement uncertainty of fibre dimension and flaws of the fibre, either during plant growth, harvesting, or at peeling process. The raw of stalks that had been delivered on the strands rolls are also potentially give variability of the tensile modulus and tensile strength on our results.

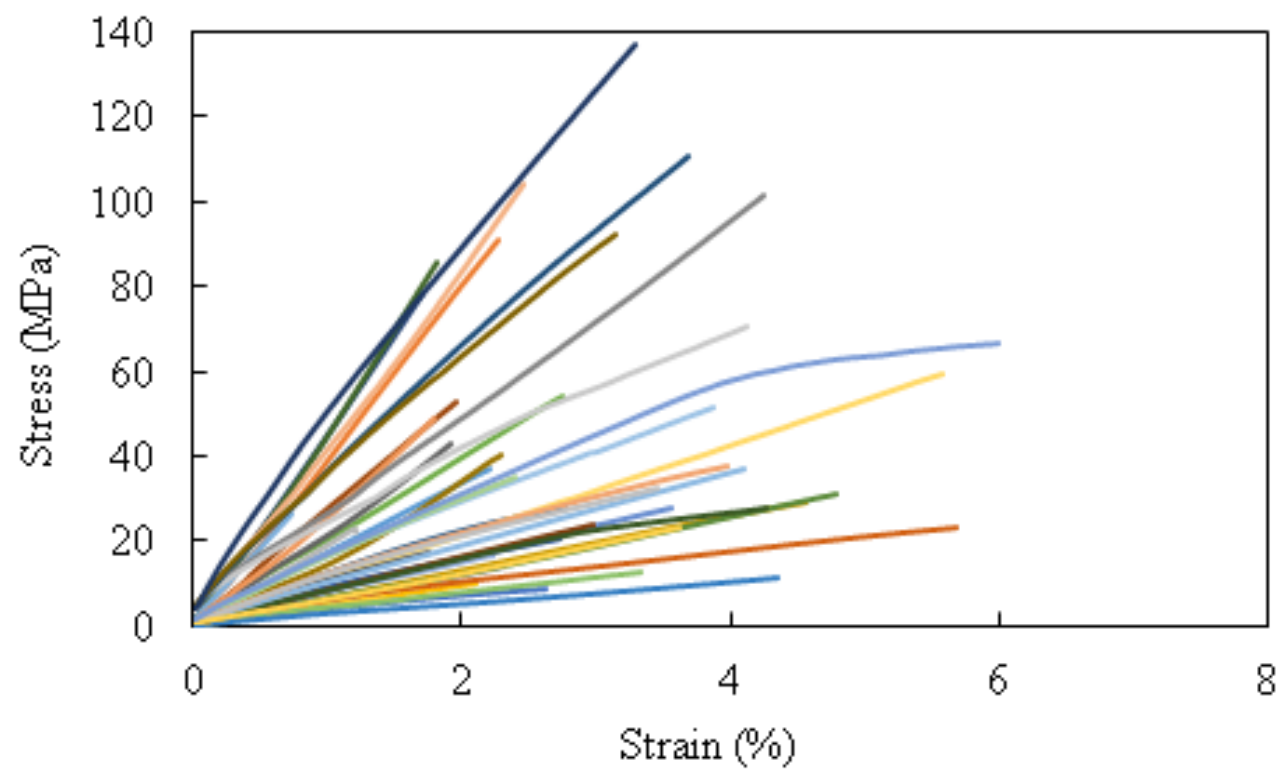

Figure 1 Stress versus strain curves of ECP fibre in water-wet condition. The curves represent 41 different specimens. 


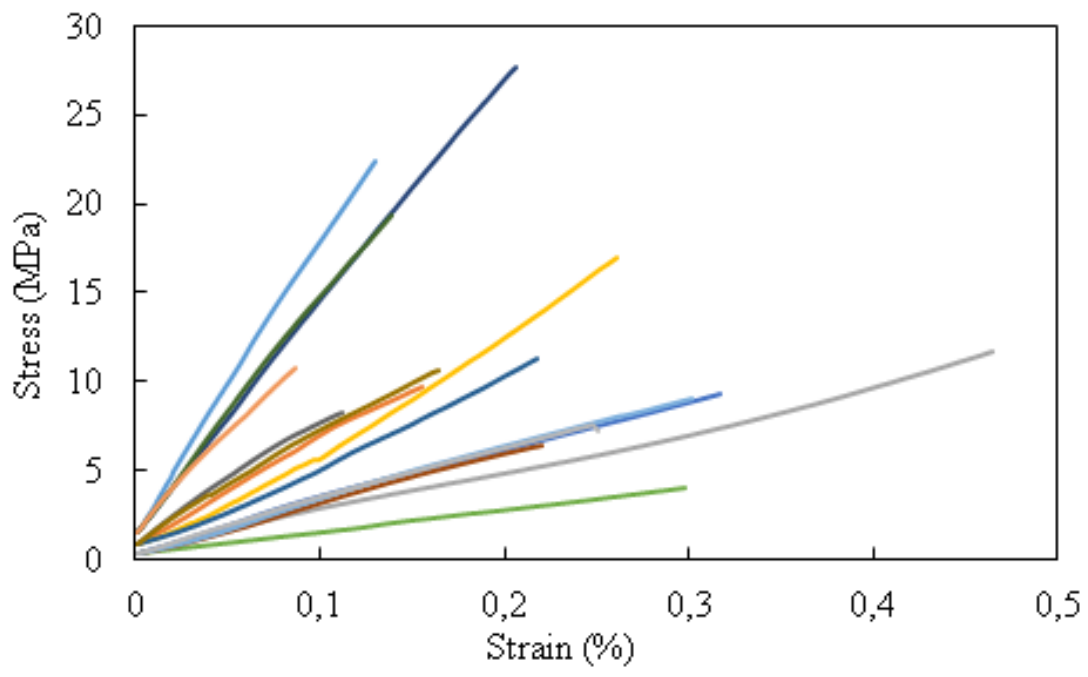

Figure 2 Stress versus strain curves of ECP fibre on dried condition. The curves represent 15 different specimens.

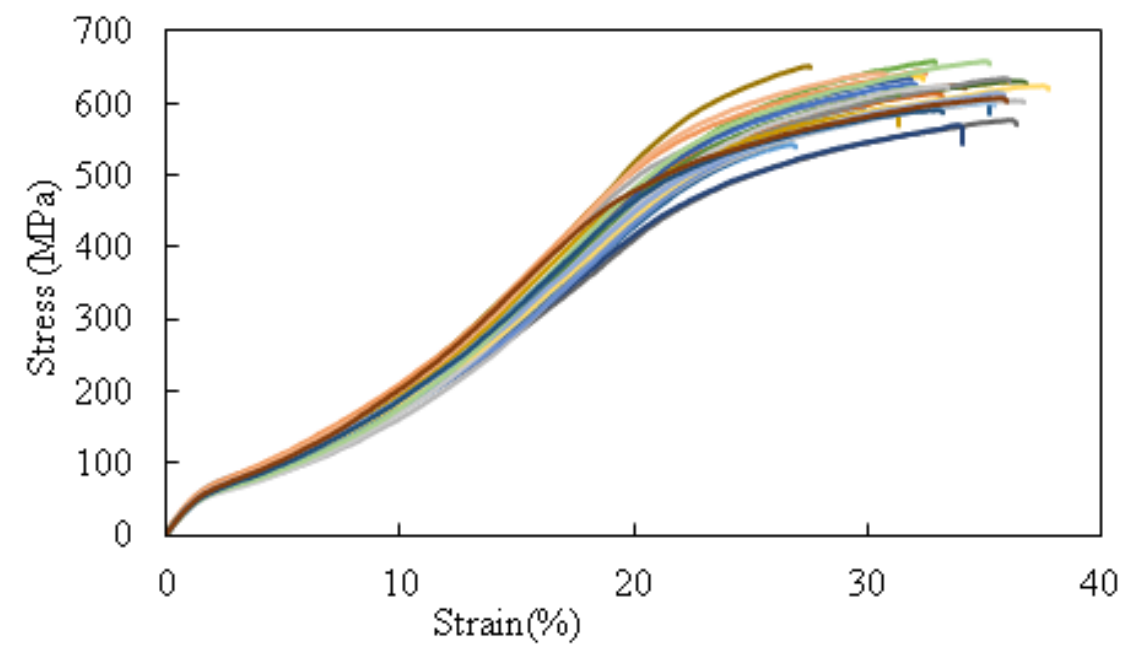

Figure 3 Stress versus strain curves of synthetic nylon 140. The curves represent 32 different specimens. The nylon diameter is $140 \mu \mathrm{m}$. E for Nylon is $2-3.6 \mathrm{GPa}[16]$.

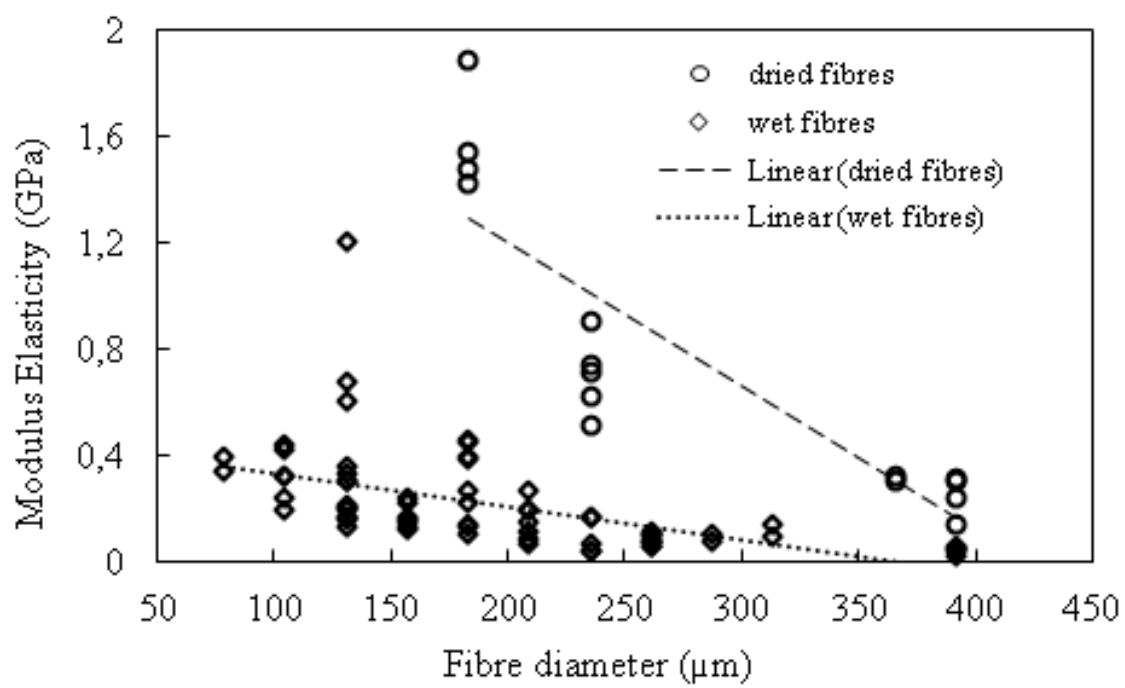

Figure 4 Fit line plot modulus of elasticity versus fibre diameter of ECP fibre. The dried fibres slope $(\mathrm{S}=0.288 ; \mathrm{R} 2=$ $0.75)$ is steeper than wet fibres $(S=0.0996 ; R 2=0.47)$. 


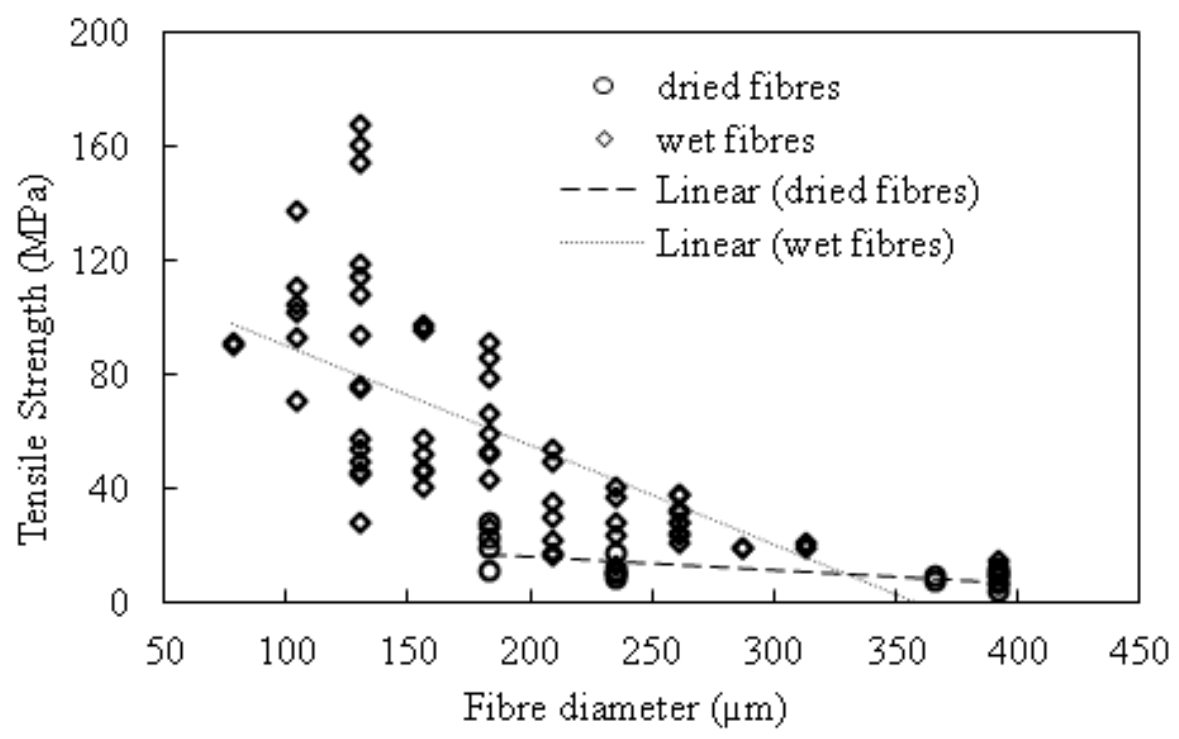

Figure 5 Fit line plot of tensile strength versus fibre diameter of ECP fibre. The wet fibres slope $(\mathrm{S}=4.946 ; \mathrm{R} 2=$ $0.45)$ is steeper than dried fibres $(S=19.878 ; \mathrm{R} 2=0.62)$.

\section{CONCLUSION}

Stress strain curves produced by tensile tests found ECP fibres to have similar mechanical behaviour to artificial polymers like nylon. On this particular study, both dried and wet fibres tested showed considerable variability in mechanical behaviour similar to other biological materials. There were many rejected samples during testing due to breakage close to the grips or obvious flaws on the fibre surface. In a commercial application, these fibres might exacerbate variability. Natural materials are inherently heterogeneous [19] and flaws may have been introduced from fibre extraction or through biological decay of the raw ECP stalks.

Material preparation will also affect effectiveness in forming a robust mat and mud cake. Left dry, the low failure strain and tensile strength of fibres will greatly decrease effectiveness. However, for a water-based drilling mud, this is very easy to remedy by allowing for sufficient time for the fibres to wet up. The stiffness of the fibre gives flexible bending across opening fractures on loss circulation zones. The relatively smaller elastic modulus would allow for easy handling and injection of drilling muds amended with the fibres.

ECP has the potential to seal opening fissures of lost circulation zones due to lower modulus of elasticity, mechanical strength and its stiffness similar with bagasse and wood [20]-[22].

\section{ACKNOWLEDGMENTS}

I would like to express my sincere regards and gratitude to the Ministry of Energy and Mineral Resources, Republic of Indonesia for funding this study.

\section{REFERENCES}

[1] R. Caenn, H. C. H. Darley, and G. R. Gray, Composition and properties of drilling and completion fluids. Gulf professional publishing, 2011.

[2] J. J. Azar and G. R. Samuel, Drilling engineering. PennWell books, 2007.

[3] A. N. Okon, F. D. Udoh, and P. G. Bassey, "Evaluation of rice husk as fluid loss control additive in water-based drilling mud," 2014.

[4] S. P. B. Almagro, C. Frates, J. Garand, and A. Meyer, "Sealing fractures: Advances in lost circulation control treatments," Oilf. Rev., vol. 26, no. 3, pp. 4-13, 2014.

[5] T. M. Nayberg, "Laboratory study of lost circulation materials for use in both oil-based and water-based drilling muds," SPE Drill. Eng., vol. 2, no. 03, pp. 229-236, 1987.

[6] R. J. White, "Lost-Circulation Materials and Their Evaluation," Am. Pet. Inst., pp. 352-359, 1956.

[7] I. Ismail, A. B. M. Nor, M. F. Hamid, and A. R. Ismail, "The impact of durian rind in water-based mud in combating lost circulation," J. Teknol., vol. 74, no. 1, 2015.

[8] V. Mahto and V. P. Sharma, "Rheological study of a water based oil well drilling fluid," J. Pet. Sci. Eng., vol. 45, no. 1-2, pp. 123-128, 2004.

[9] M. E. Hossain and M. Wajheeuddin, "The use of grass as an environmentally friendly additive in 
water-based drilling fluids," Pet. Sci., vol. 13, no. 2, pp. 292-303, 2016.

[10] M. Amanullah, J. Ramasamy, M. K. Al-Arfaj, and S. Aramco, "Application of an indigenous ecofriendly raw material as fluid loss additive," J. Pet. Sci. Eng., vol. 139, pp. 191-197, 2016.

[11] M. T. Al-saba, R. Nygaard, A. Saasen, and O.-M. Nes, "Lost circulation materials capability of sealing wide fractures," 2014.

[12] B. Jain et al., "Successful implementation of engineered fiber based loss circulation control solution to effectively cure losses while drilling, cementing and work over operations in Oman," 2013.

[13] M. Soerjani, "Weed management and weed science development in Indonesia," in Proc. 6th. Conf. I, 1977, vol. 31, no. 41, pp. 31-41.

[14] B. Gopal, "Aquatic plant studies 1. Water hyacinth," City, Netherlands Elsevier Sci., 1987.

[15] L. S. Widyanto, "Studies on the growth and control of water hyacinth (Eichhornia crassipes (Mart. Solms))," Int. J. Pest Manag., pp. 460-464, 1975.

[16] M. F. Ashby and D. R. H. Jones, Engineering materials 1: an introduction to properties, applications and design, vol. 1. Elsevier, 2012.
[17] E. P. Knoshaug, B. Shi, T. G. Shannon, M. M. Mleziva, and P. T. Pienkos, "The potential of photosynthetic aquatic species as sources of useful cellulose fibers - a review," J. Appl. Phycol., vol. 25, no. 4, pp. 1123-1134, 2013.

[18] A. V. R. Prasad, K. M. Rao, A. Gupta, and B. V Reddy, "A Study on flexural properties of wildcane grass fiber-reinforced polyester composites," $J$. Mater. Sci., vol. 46, no. 8, pp. 2627-2634, 2011.

[19] K. J. Niklas, H. Spatz, and J. Vincent, "Plant biomechanics: an overview and prospectus," Am. J. Bot., vol. 93, no. 10, pp. 1369-1378, 2006.

[20] H. Abral et al., "Mechanical properties of water hyacinth fibers-polyester composites before and after immersion in water," Mater. Des., vol. 58, pp. 125-129, 2014.

[21] C. C. Gunnarsson and C. M. Petersen, "Water hyacinths as a resource in agriculture and energy production: A literature review," Waste Manag., vol. 27, no. 1, pp. 117-129, 2007.

[22] P. Methacanon, U. Weerawatsophon, N. Sumransin, C. Prahsarn, and D. T. Bergado, "Properties and potential application of the selected natural fibers as limited life geotextiles," Carbohydr. Polym., vol. 82, no. 4, pp. 1090-1096, 2010. 